\title{
ANÁLISE DA GESTÃO MUNICIPAL NA MANUTENÇÃO PREVENTIVA E CORRETIVA DOS TÚNEIS DO MUNICÍPIO DO RIO DE JANEIRO
}

\author{
Ivan Eduardo Santos Raphael ${ }^{1}$ \\ Reiner Olíbano Rosas ${ }^{2}$
}

\begin{abstract}
RESUMO: O objetivo deste estudo foi mostrar a importância da manutenção preventiva e corretiva de forma regular nos túneis localizados no município do Rio de Janeiro, para assim mitigar e até mesmo evitar os riscos de desabamentos. Como justificativa, a partir dos resultados obtidos, o estudo poderá servir de subsídio para a adoção de uma rotina permanente de prevenção de riscos de desabamentos. Para o desenvolvimento do presente estudo foi realizada uma ampla revisão bibliográfica. A pesquisa feita teve um aspecto de exploratória-descritiva, tendo um caráter qualitativo. Concluiu-se que, quando há uma forte necessidade de implementação de sistemas de manutenção em obras de qualquer nível ou tipo de uso, no caso de obras públicas, sobretudo em túneis, a questão da manutenção se mostra de suma importância. Primeiramente, porque tem-se uma ampla circulação de usuários, que induz a uma deterioração natural do equipamento e, considerando que são estruturas fechadas, submetidas a intensas ações agressivas tais como infiltrações, subpressões, dentre outras ações, este sistema de prevenção passa a ser ainda mais essencial.
\end{abstract}

Palavras-Chave: Manutenção Preventiva e Corretiva. Mitigação. Rio de Janeiro. Túneis.

ABSTRACT: The aim of this study was to show the importance of regular preventive and corrective maintenance in tunnels located in the city of Rio de Janeiro, in order to mitigate and even avoid the risk of landslides. As a justification, based on the results obtained, the study may serve as a subsidy for the adoption of a permanent routine for preventing the risks of landslides. For the development of the present study, an extensive bibliographic review was carried out. The research carried out had an exploratory-descriptive aspect, having a qualitative character. It was concluded that, when there is a strong need to implement maintenance systems in works of any level or type of use, in the case of public works, especially in tunnels, the issue of maintenance is of paramount importance. First, because there is a wide circulation of users, which induces a natural deterioration of the equipment and, considering that they are closed structures, subjected to intense aggressive actions such as infiltration, underpressure, among other actions, this prevention system becomes even more essential.

Keywords: Mitigation. Preventive and Corrective Maintenance. Rio de Janeiro Tunnels.

\footnotetext{
${ }^{1}$ Mestrando em Defesa e Segurança Civil pela Universidade federal Fluminense (UFF). Possui MBA em Gestão Empresarial pela Universidade Gama Filho. Atualmente é servidor público na Universidade Federal Fluminense, com lotação na Superintendência de Arquitetura Engenharia e Patrimônio.

${ }^{2}$ Doutor em Geografia pela Universidade Federal do Rio de Janeiro (200o). Atualmente é Professor Associado da Universidade Federal Fluminense (UFF), onde atua na área de Geociências com ênfase em Gênese no Estudo dos Solos, Processo Erosivo, Dinâmica de Bacias Hidrográficas, Geoprocessamento e Redução de Riscos de Desastres.
} 


\section{INTRODUÇÃO}

Observa-se que, no Brasil, ainda não há um pleno conhecimento técnico-científico sistemático e mais amplo acerca da avaliação das condições de estabilidade estrutural de túneis, notadamente os mais antigos. De maneira comum, tal avaliação, quando se faz imprescindível, é realizada conforme as características de cada caso que se exibe e, igualmente, de acordo com as experiências e conhecimentos dos engenheiros especializados em projetos e execução de tais estruturas.

Frente a isto, no momento em que se for fazer manutenções apropriadas e recorrentes que fazem parte de um procedimento de gerenciamento mais extenso, admitese a garantia de maior vida útil e de suficientes comportamentos estruturais e funcionais, reconhecendo, por meio de vistorias recorrentes, os danos existentes, diagnosticando-os e recomendando as ações para patologias.

Sendo assim, a partir dos resultados obtidos, o estudo poderá servir de subsídio para a adoção de uma rotina permanente de abertura de processos licitatórios que tenham por objeto a manutenção preventiva e corretiva de todos os túneis do município do Rio de Janeiro, com a consequente manutenção regular para prevenir o risco de deslizamentos.

O presente estudo teve por objetivo mostrar a importância da manutenção preventiva e corretiva de forma regular nos túneis localizados no município do Rio de Janeiro, para assim mitigar e até mesmo evitar os riscos de desabamentos. Como objetivos específicos, buscou-se analisar o real estado de conservação dos túneis na área geográfica da cidade do Rio de Janeiro, relacionando com o orçamento disponibilizado para a Secretaria de Infraestrutura e Habitação do município e com a abertura de processo licitatório pelo município para a manutenção preventiva e corretiva dos túneis nos últimos dez anos.

A pesquisa para o tema proposto foi desenvolvida identificando previamente todos os túneis construídos no município do Rio de Janeiro, o ano de construção, o histórico de obras para manutenção preventiva e corretiva, bem como o histórico de desabamentos de cada túnel.

Em um segundo momento, foram apurados nos últimos dez anos, na cidade do Rio de Janeiro, o orçamento destinado pela prefeitura para a manutenção preventiva e 
corretiva dos túneis, e a abertura de processo licitatório e seus respectivos contratos, visando assim a manutenção preventiva e corretiva dos túneis. Por fim, todas as informações obtidas foram reunidas para relacionar o estado da gestão municipal na manutenção preventiva e corretiva dos túneis do município do Rio de Janeiro ao risco de desabamento.

\section{REVISÃO DA LITERATURA}

Segundo Vidal; Azevedo e Castro (2013, p. 44), "manutenção é a ação de manter, sustentar, consertar ou conservar alguma coisa ou algo aumentando consequentemente sua vida útil”. A manutenção tem o intuito de reparar ou repor algo que está depreciado, ou que não funciona corretamente, consertando para que volte a desenvolver a função requerida de sua fase inicial.

O município do Rio de Janeiro tem trinta e um túneis, que facilitam o deslocamento do trânsito de veículos através de obstáculos geográficos. Entretanto, a fluidez do trânsito fica prejudicada em determinados momentos, pelo fato de um túnel não ter recebido as manutenções preventivas e corretivas adequadas.

Sabe-se que o município do Rio de Janeiro concentra altos índices de acidentes, muitos deles por descuido das autoridades competentes, no que tange ao processo de verificação do estado de conservação das construções das obras do Rio de Janeiro, mais especificamente nos túneis da cidade. Atualmente, vários túneis localizados no município do Rio de Janeiro não passam por um processo constante e contínuo de manutenções, para que possam ser verificados possíveis danos causados pelo tempo ou pessoas.

As tarefas de manutenção são geralmente de dois tipos, tais como: planejadas e não planejadas. A manutenção planejada pode ser preventiva ou corretiva (incluindo manutenção diferida), enquanto a manutenção não planejada é principalmente corretiva, o que inclui qualquer manutenção de emergência. Novamente, a manutenção preventiva pode ser agendada e a outra pode se basear nas condições do equipamento, conhecida como manutenção baseada em condições (BRANCO FILHO, 2008).

Assim, de acordo com os ensinamentos de Kardec e Nascif (2009, p. 78), a forma da manutenção pode ser das seguintes maneiras: "manutenção pré-planejada; manutenção 
planejada; manutenção de parada; manutenção de avarias; manutenção de emergência”.

A construção de um túnel pode ser uma solução para um problema específico, pois, em função de sua complexidade, normalmente é adotado como última alternativa. Trata-se de uma alternativa que encontra inúmeros obstáculos a serem ultrapassados no seu processo de construção, seja um oceano, uma rocha, uma montanha, e até mesmo uma rota de transporte complexa. Mesmo diante desse cenário complexo para a construção de um túnel, o município do Rio de Janeiro tem 3I túneis, isto devido à sua topografia peculiar; eles estão espalhados por toda a cidade, como mostra a Figura 6 (DURAZZO, 2006).

O cenário natural paradisíaco do município mostrou-se um obstáculo a ser vencido durante o processo de expansão urbana da cidade do Rio de Janeiro. Nessa "quase luta contra a natureza", no processo de dispersão e ocupação humana da cidade, surgiu a necessidade de construção dos túneis, que ligariam diversos pontos do município, melhorando o fluxo do trânsito e fazendo a incorporação de áreas periféricas que estavam isoladas (CELESTINO, 2006).

O túnel mais antigo foi inaugurado em 1887: o Túnel da Rua Alice, também chamado de Túnel Rio Comprido-Laranjeiras. Os mais modernos foram inaugurados em 2016. Um deles, passando pelo Complexo do Joá (Túneis de São Conrado, Joá, Engenheiro Luís Jacques de Moraes e Paulo Cézar Figueiredo), Porto Maravilha e TransOlímpica, e, por último, o Túnel da Marítima, que liga a região da Estação Ferroviária da Central do Brasil ao Cais do Porto, perfurado no Morro da Providência, recém ativado no ano de 2017 (MOREIRA, 2006).

Sendo assim, reitera-se que a principal função de um túnel é tornar viável a passagem de fluxo, permitindo o rápido deslocamento e facilitando a evolução do trânsito, de uma forma geral. A seguir, serão apresentados os trinta e um túneis em ordem cronológica de construção (PREFEITURA DO RIO DE JANEIRO, 202I).

\section{METODOLOGIA}

Para o desenvolvimento do presente estudo foi realizada uma vasta revisão bibliográfica. Tal método foi aplicado por meio de obtenção e análise de artigos científicos, dissertações, teses e publicações. Todo o material foi obtido por meio de sites de busca 
eletrônica e bibliotecas virtuais, tais como Google Acadêmico e Scientific Electronic Library Online (SciELO). Como critérios de seleção, optou-se por selecionar apenas obras publicadas entre os anos de 200I-2021.

Posteriormente a etapa de levantamento bibliográfico, foi então feita uma triagem e seleção do material que aborda em característico a temática estudada. Os descritores utilizados na busca eletrônica foram os seguintes: Manutenção Preventiva e Corretiva; Rio de Janeiro; Túneis. Inicialmente, foram obtidos 147 resultados na busca eletrônica, sendo ao fim aproveitados 20 trabalhos.

A pesquisa feita teve um aspecto de exploratória-descritiva, tendo um caráter qualitativo. De acordo com Gil (2007), a análise qualitativa de dados, trata-se de um fenômeno recentemente retomado, que se caracteriza por ser um processo indutivo que tem como foco a fidelidade ao universo de vida cotidiano dos sujeitos, estando baseada nos mesmos pressupostos da chamada pesquisa qualitativa.

A abordagem aproveitada na presente pesquisa foi a qualitativa, a qual teve-se a coleta de informações pertinentes para em seguida serem expostas e avaliadas, além da observação de documentos, tendo-se a preocupação de colher uma maior quantidade de elementos, visando assim um entendimento maior e mais profundo da problemática estudada.

\section{RESULTADOS E DISCUSSÃO}

$\mathrm{Na}$ última década, houve uma diminuição considerável no orçamento da prefeitura do Rio de Janeiro na gestão dos túneis municipais. Com isto, a manutenção precária dos túneis que cruzam os morros da cidade - incluindo o Túnel Acústico Rafael Mascarenhas, na Gávea - pode ser igualmente explicada em números (O GLOBO, 2019).

Pode-se dizer que o colapso da estrutura se trata de um reflexo da redução no orçamento para manutenção dos túneis, passarelas, viadutos e pontes. No ano de 2019, foram investidos somente $\mathrm{R} \$ 439$ mil em manutenção. A dotação proposta a recuperação e construção se encontra zerada, pois, o orçamento, que era de R\$ II,5 milhões, foi contingenciado (DIÁRIO DO RIO, 2019).

Conforme um levantamento realizado pelo gabinete da vereadora Teresa Bergher, 
no sistema FINCON (de execução orçamentária) e nos prestamentos de contas da prefeitura, analisa-se que a prefeitura acaba colocando a vida da população em risco deixando de lado ações importantes para a cidade (O GLOBO, 2019).

De acordo com este citado levantamento, na manutenção (serviços para conservar o conforto e a segurança) de túneis, passarelas, viadutos e pontes, o orçamento foi reduzido drasticamente. No ano de 2013, foram aplicados $\mathrm{R} \$ 8,7$ milhões. Já em 2019, foram liquidados (autorização para pagar) R \$ I,I8 milhão para quitar estas contas (DIÁRIO DO RIO, 2019).

Portanto, se mostra preocupante a situação orçamentária para manutenção preventiva e corretiva dos túneis do município do Rio de Janeiro. $\mathrm{O}$ ano de 2019 já se trata do ano de menor investimento em manutenção estrutural dos túneis, como mostra a Tabela I. Do orçamento de $\mathrm{R} \$ 505$ mil previsto para o ano de 2019, a Prefeitura liquidou $\mathrm{R} \$$ 439 mil (DIÁRIO DO RIO, 2019).

TABELA I - SITUAÇÃO ORÇAMENTÁRIA PARA MANUTENÇÃO PREVENTIVA E CORRETIVA DOS TÚNEIS DO MUNICÍPIO DO RIO DE JANEIRO, 2009-2019

\begin{tabular}{|c|c|c|c|c|c|}
\hline \multicolumn{6}{|c|}{$\begin{array}{l}\text { Tipo: Atividade } \\
\text { Objetivo Especifico: Manter as condiçōes de conforto e segurança das obras-de-arte } \\
\text { especiais (viadutos, pontes, passarelas e túneis) da cidade do Rio de Janeiro. }\end{array}$} \\
\hline ANO & $\begin{array}{l}\text { DOTAÇĀO } \\
\text { INICIAL }\end{array}$ & $\begin{array}{l}\text { DOTAÇĀO } \\
\text { FINAL }\end{array}$ & $\begin{array}{l}\text { VARIAÇĀO } \\
\text { ENTRE AS } \\
\text { DOTAÇŌES }\end{array}$ & $\begin{array}{l}\text { DESPESA } \\
\text { LIQUIDADA }\end{array}$ & $\begin{array}{l}\text { VAR. ANUAL } \\
\text { DA } \\
\text { LIQUIDAÇĀO }\end{array}$ \\
\hline 2009 & 2.630 .551 & 1.548 .921 & -1.081 .630 & $1,497.656$ & - \\
\hline 2010 & 2.063 .605 & 1.367 .961 & -695.644 & 1.367 .929 & -129.727 \\
\hline 2011 & 2.021 .182 & 2.381 .830 & 360.649 & 2.323 .508 & 955.580 \\
\hline 2012 & 15.552 .086 & 5.715 .530 & -9.836 .556 & 5.715 .245 & 3.391 .736 \\
\hline 2013 & 8.307 .674 & 9.191 .067 & 883.383 & 8.860 .794 & 3.145 .549 \\
\hline 2014 & 4.856 .464 & 4.856 .464 & 0 & 4.855 .204 & $-4.005,590$ \\
\hline 2015 & 6.463 .570 & 1.744 .309 & -4.719 .260 & 1.255 .222 & -3.599 .982 \\
\hline 2016 & 1.780 .395 & 1.780 .395 & 0 & 1.779 .339 & 524.116 \\
\hline 2017 & 1.711 .836 & 1.283 .877 & -427.959 & 1.197 .411 & -581.927 \\
\hline 2018 & 1.229 .872 & 2.785 .519 & 1.555 .647 & 1.198 .069 & 658 \\
\hline 2019 & 653,837 & 505.539 & -148.298 & 439.116 & -758.953 \\
\hline
\end{tabular}

Fonte: Diário do Rio (2019) 
A título de comparação, a Prefeitura do Rio, no período de 2009-2016, investiu em média $R \$ 3,4$ milhões, enquanto que, no período de 2017-2020, sustentou uma média em $\mathrm{R} \$$ I,2 milhão - representando um corte de 65\% nesse tipo de atividade. Portanto, $\mathrm{R} \$ 2,2$ milhões a menos em despesas com manutenção. A baixa execução de 2019 diminuiu ainda mais a média de gastos da gestão atual, como mostra a Gráfico I (DIÁRIO DO RIO, 20I9).

O DA MÉDIA DE GASTOS COM MANUTENÇÃO DE TÚNEIS NO RIO DE JANEIRO

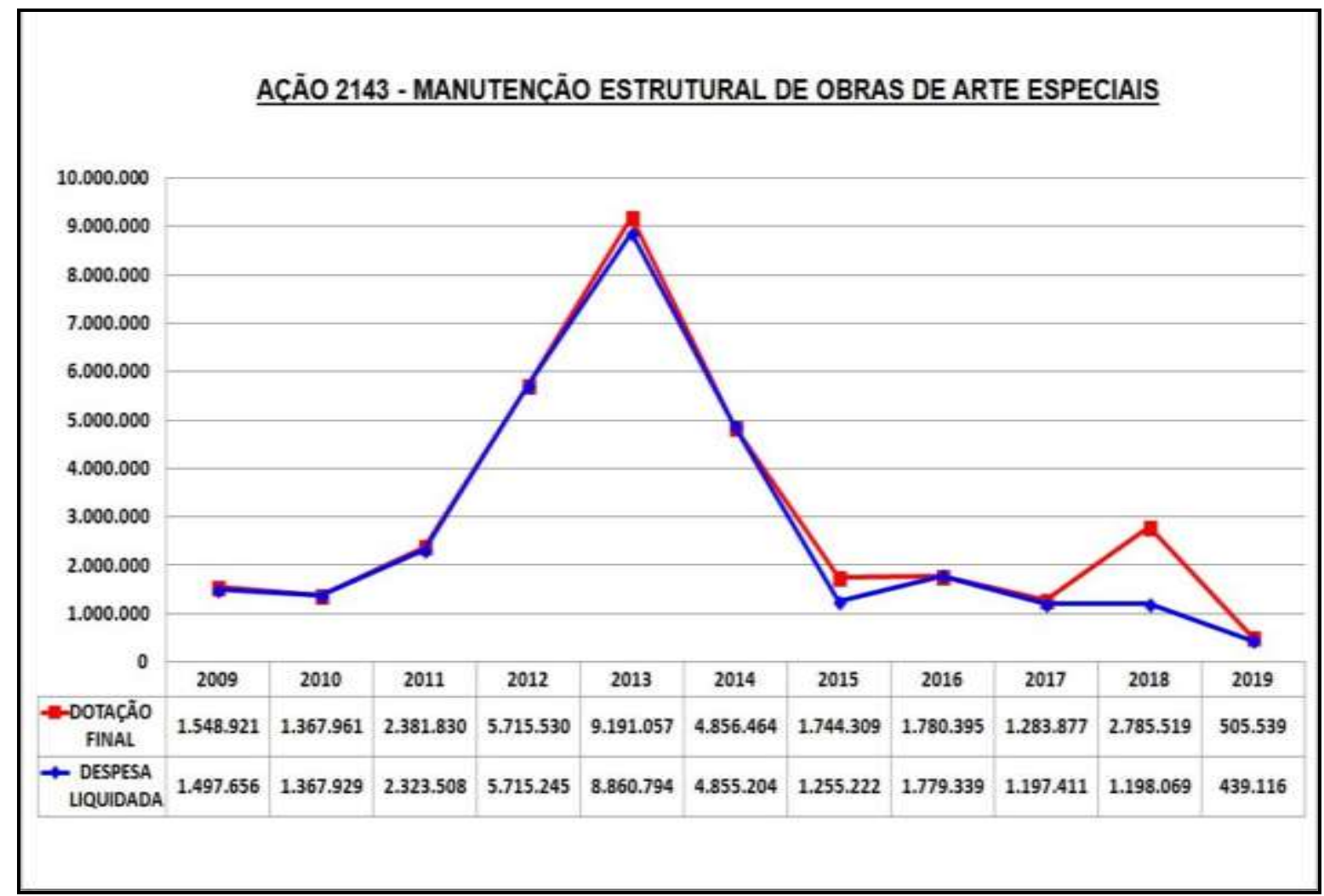

Fonte: Diário do Rio (2019)

Assim, para a construção e recuperação das obras, observa-se no gráfico acima que o período de 2017-2020 saiu de uma execução zerada no ano de 2018 para investir, até o momento, $\mathrm{R}_{\$}$ 3,6 milhões. Todavia, os números ficam bem abaixo do período anterior (DIÁRIO DO RIO, 20I9).

A Coordenadoria de Vias Urbanas é responsável por controlar e operar os serviços de conservação e manutenção da pavimentação asfáltica e em concreto, e do sistema de 
drenagem em vias expressas e vias especiais do município, tais como a Avenida Brasil, Linha Vermelha, Autoestrada Lagoa Barra, Estrada Grajaú-Jacarepaguá, os corredores TransCarioca e TransOeste, além dos túneis municipais. Deste modo, o planejamento dos trabalhos ocorre através de três gerências principais, a saber: Gerência de Vias Especiais; Gerência da TransOeste; Gerência da TransCarioca (PREFEITURA DO RIO, 2020).

Gerência de Vias Especiais: atende aos corredores expressos e especiais da cidade, como avenidas Brasil e Niemeyer, Linha Vermelha, Estrada Grajaú-Jacarepaguá e túneis da cidade. Dentre os serviços realizados, se encontram a recuperação da pavimentação asfáltica, manutenção e reparos do sistema de drenagem, recuperação de muretas e defensas metálicas (PREFEITURA DO RIO, 2020).

Gerência da TransOeste: atende aos $30 \mathrm{~km}$ de extensão aproximadamente com serviços de recuperação de trechos da pavimentação asfáltica e em concreto, limpeza mecânica e manual do sistema de drenagem. Executa também a monitoração através de câmeras no túnel vice-presidente José Alencar, na Grota Funda, para realização de serviços de manutenção e conservação. Dentre eles, tem-se pintura e substituição de placas cimentícias, manutenção da iluminação e das quarenta e oito câmeras do túnel (PREFEITURA DO RIO, 2020).

Gerência da TransCarioca: atende aos $40 \mathrm{~km}$ aproximadamente da via com serviços de recuperação de trechos da pavimentação asfáltica e em concreto, limpeza mecânica e manual do sistema de drenagem e reposição e restauração de grades de segurança para pedestres que ficam no transcorrer da via (PREFEITURA DO RIO, 2020).

A Concessionária Porto Novo devolve a gestão dos túneis Marcello Alencar e Rio45o para a prefeitura. Os dois túneis são tidos como eixos essenciais de mobilidade urbana como alternativa para se chegar ao Centro da cidade através do Aterro do Flamengo (Marcello Alencar) e para a integração dos bairros do Centro e da Saúde (Rio45o) (PREFEITURA DO RIO, 2020).

Sendo assim, na questão do orçamento, observa-se que as despesas com manutenção de túneis caíram de maneira drástica, de 1.198, 069, em 2018, para 439.116, em 2019. A Gráfico 2 apresenta um gráfico com a comparação de gastos em números no transcorrer do tempo. 


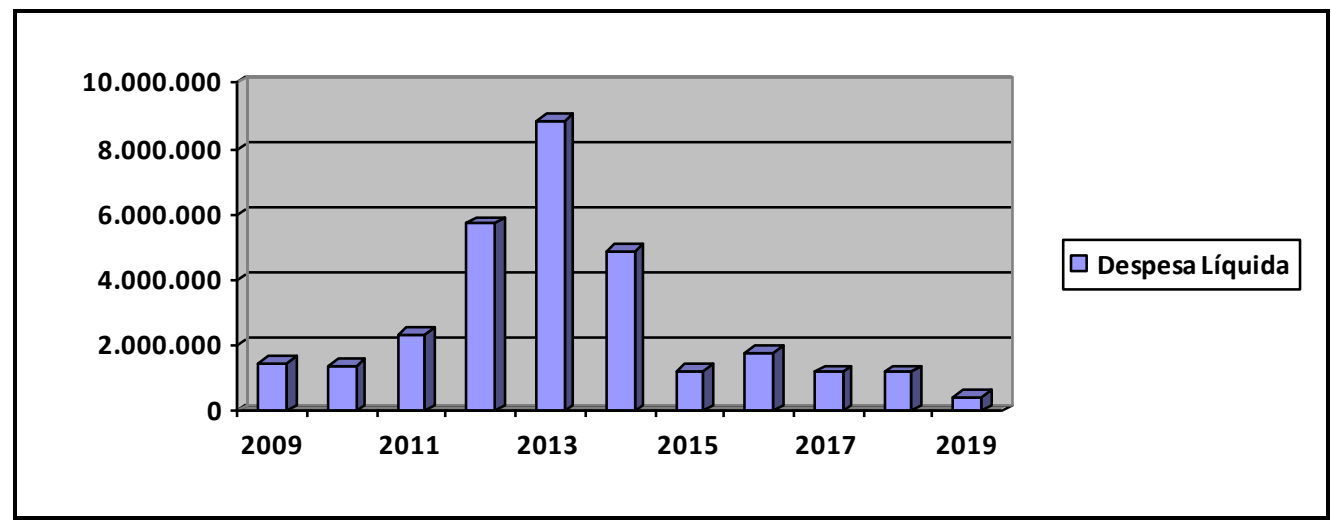

Fonte: Próprio autor (202I)

Com o gráfico acima, observa-se que o maior gasto se deu no ano de 2013. Deste modo, analisando o real estado de conservação dos túneis na área geográfica da cidade do Rio de Janeiro, relacionando com o orçamento disponibilizado para a Secretaria de Infraestrutura e Habitação do município e com a abertura de processo licitatório pelo município para a manutenção preventiva e corretiva dos túneis nos últimos dez anos. Portanto, desde o ano de 20I4, os gastos vêm caindo drasticamente. Isto mostra que a prefeitura do Rio coloca a vida das pessoas em risco, quando deixa de lado ações fundamentais para a cidade.

\section{CONCLUSÃO}

Concluiu-se que, quando há uma forte necessidade de implementação de sistemas de manutenção em obras de qualquer nível ou tipo de uso, no caso de obras públicas, sobretudo em túneis, a questão da manutenção se mostra de suma importância. Primeiramente, porque tem-se uma ampla circulação de usuários, que induz a uma deterioração natural do equipamento e, considerando que são estruturas fechadas, submetidas a intensas ações agressivas tais como infiltrações, subpressões, dentre outras ações, este sistema de prevenção passa a ser ainda mais essencial.

Portanto, sistemas como túneis precisam de um plano de manutenção com uma gestão bem qualificada para impedir danos maiores e com proporções quase sempre 
desastrosas, podendo paralisar uma cidade inteira, como visto nos casos apresentados do Túnel Acústico e Rebouças.

Assim, frente a situação atual dos túneis municipais do Rio de Janeiro, cujas manifestações patológicas já vem dificultando e até mesmo impedindo em algumas condições o fluxo de automóveis com sérias consequências na rotina dos usuários destes equipamentos, torna-se imprescindível que haja a implementação de um sistema de manutenção, de maneira a admitir a programação de todas as ações de prevenção e correção imprescindíveis ao bom funcionamento dos mesmos.

De tal modo, este sistema pode vir a admitir a tomada de decisões céleres e eficientes em informações técnicas fundamentadas em inspeções feitas por profissionais especializados e devidamente habilitados. As inspeções cotidianas poderão ser feitas simplesmente de maneira visual, sem a necessidade de instrumentos, entretanto, em algumas circunstâncias, tornam-se imprescindíveis análises mais aprofundadas que podem sugerir a concretização de ensaios de laboratório e em medições de equipamentos mais complexos, dependendo da seriedade detectada.

Por fim, foi possível concluir que a melhor forma de impedir um estado patológico é a prevenção e programa de conservação. Com isto, é possível dizer que a manutenção preventiva é provocada não somente por um projeto correto ou por uma implantação conforme os parâmetros de qualidade, entretanto, igualmente por um programa de manutenção estrutural.

Ademais, como sugestão para trabalhos futuros, recomenda-se estudos que possam trazer e discutir soluções viáveis para pontes aquáticas que apresentam problemas referentes a substituição de estruturas danificadas por novas pontes, para assim atuar de forma veloz e competente na implantação de tais estruturas. Além do mais, uma vez que o número de túneis na cidade aumenta consideravelmente no decorrer das décadas, um maior investimento deve também ser dedicado a essas vias.

\section{REFERÊNCIAS BIBLIOGRÁFICAS}

BRANCO FILHO, G. A Organização o Planejamento e o Controle da Manutenção. Rio de Janeiro: Editora Ciência Moderna LTDA., 2008. 
CElestinO, T. B. Túneis do Brasil - Apresentação. Comitê Brasileiro de Túneis. DBA Editora. Rio de Janeiro. Brasil. 2006.

DIÁRIO DO RIO. Em Io anos, 2019 é o menor investimento em manutenção de viadutos e túneis. 2019. Disponível em: <https://diariodorio.com/em-ıo-anos-2019-e-o-menorinvestimento-em-manutencao-de-viadutos-pontes-passarelas-e-tuneis/>. Acessado em 20 de agosto de 202I.

DURAZZO, F. Túneis do Brasil - Obras Subterrâneas para Saneamento da Grande São Paulo. Comitê Brasileiro de Túneis. DBA Editora. Rio de Janeiro, Brasil, 2006.

GIL, A. C. Como elaborar projetos de pesquisa. São Paulo: Atlas, 2007.

KARDEC, A; NASCIF J. Manutenção: função estratégica. $3^{\underline{a}}$ ed. Rio de Janeiro: Qualitymark: Petrobrás, 2009.

MOREIRA, C. M. da C. Túneis, Uma Herança Ancestral Rumo ao Futuro. Instituto Superior de Engenharia de Coimbra. Coimbra. Portugal. 2006.

O GLOBO. Moradores e frequentadores da Barra traçam estratégias para circular por locais que sempre alagam em dia de temporal. 2019. Disponível em: <https://oglobo.globo.com/rio/bairros/moradores-frequentadores-da-barra-tracamestrategias-para-circular-por-locais-que-sempre-alagam-em-dia-de-temporal-23607249>. Acessado em 20 de agosto de 2021.

O GLOBO. Orçamento da Prefeitura para investimentos em túneis, viadutos e pontes está zerado. 2019. Disponível em: <https://oglobo.globo.com/rio/orcamento-da-prefeiturapara-investimentos-em-tuneis-viadutos-pontes-esta-zerado-23675932>. Acessado em 20 de agosto de 2021.

PREFEITURA DO RIO DE JANEIRO. Relação dos túneis da cidade do Rio de Janeiro. 2021. Disponível em: <http://www.rio.rj.gov.br/dlstatic/IoIr/I48oi4/DLFE4266.pdf/tuneis.pdf>. Acessado em 20 de agosto de 2021.

PREFEITURA DO RIO. Cem dias: Infraestrutura investe em grandes obras e serviços como a instalação de mais de 15 mil luminárias de Led na cidade. 2020. Disponível em: $<$ https://prefeitura.rio/cidade/cem-dias-infraestrutura-investe-em-grandes-obras-e--..-.servicos-como-a-instalacao-de-mais-de-I5-mil-luminarias-de-led-na-cidade/ >. Acessado em 20 de agosto de 202I.

VIDAL, F. W. H; AZEVEDO, H; CASTRO, N. F. Tecnologia de rochas ornamentais: pesquisa, lavra e beneficiamento: CETEM/MCTI, 2013. 